\title{
APRESENTAÇÃO DO DOSSIÊ MOÇAMBIQUE E CABO VERDE - SABERES E LUTAS
}

\section{MOZAMBIQUE AND CAPE VERDE DOSSIER PRESENTATION - KNOWLEDGE AND FIGHTING}

\author{
Maria Paula Meneses ${ }^{1}$ \\ Teresa Cruz e Silva ${ }^{2}$
}

Este dossiê da Revista Debates Insubmissos centra-se em Moçambique e Cabo Verde - saberes e lutas. A partir deste contexto regional, esta edição procura contribuir para um diálogo mais aprofundado entre regiões que partilham saberes e experiências de luta no Sul global. Neste dossiê apresentam-se alguns dos problemas que caracterizam o contexto sociopolítico moçambicano, enquanto desafio epistémico amplo, assim como uma reflexão eco-literária centrada em Cabo Verde, na costa atlântica africana. Este número integra também na Seção Pautas Insubmissas - Mais Moçambique - que apresenta uma entrevista que trabalha vários temas candentes da realidade moçambicana, com o enfoque nos movimentos sociais alternativos, sobretudo de jovens, que hoje avançam com propostas políticas alternativas, desafiando a apropriação do jogo político pelos principais partidos moçambicanos. Além de uma experiência inovadora de aproveitamento de resíduos de papel para produção de carvão ecológico na cidade de Nampula. No seu conjunto, estas duas seções apresentam pistas interdisciplinares que procuram contribuir para um diálogo produtivo no

\footnotetext{
${ }^{1}$ Investigadora coordenadora do Centro de Estudos Sociais da Universidade de Coimbra, integrando o núcleo de estudos sobre Democracia, Cidadania e Direito (DECIDe). Doutora em antropologia pela Universidade de Rutgers (EUA) e Mestre em História pela Universidade de S. Petersburgo (Rússia). Lecciona em vários programas de doutoramento do CES, sendo co-coordenadora do programa de doutoramento em 'Póscolonialismos e cidadania global'

2 Doutora em Ciências Sociais na Universidade de Bradford, Grã-Bretanha. Graduada em História pela Universidade de Lourenço Marques/Moçambique. Pesquisadora associada da WLSA Moçambique (WomenandLaw in Southern Africa), e membro do CODESRIA - Conselho para o Desenvolvimento da Pesquisa em Ciências Sociais da África.
} 
Sul e com o Sul, estendendo-se da literatura à ciência política, dos movimentos sociais às experiências de inovação ecológica.

O desafio de conhecer o Sul pelas vozes e reflexões do Sul impelindo-nos a ir além das categorizações geopolíticas marcadas pela herança colonial, procurando enfatizar a opressão económica, política, epistémica e ontológica que marca o mundo contemporâneo. De facto, as condições no Sul Global só são compreensíveis quando são definidas em relação às situações que caracterizam o Norte Global; processos e estruturas globais fazem de todos os países parte de um mundo cada vez mais integrado. Essencial a este diálogo amplo sobre realidades concretas do Sul, um sul epistémico e não geográfico (SANTOS, 2014) é a necessidade de um inter-conhecimento, assente na análise de realidade concretas (MENESES, 2016). Esta concetualização do Sul global trouxe consigo a reintrodução dos contributos de África, nas reflexões epistémicas sobre o mundo e as suas lutas, para além das perspetivas eurocêntrica. Convém não esquecer que muitas das representações do continente africano são um objeto de conhecimento inventado pelo Ocidente. Com efeito, o projeto do imperialismo europeu não se limitou à dominação política, mas também se manifesta na colonização da mente, como o sublinha Ngugi wa Thiong'o (1993).

Os tempos contemporâneos revelam que o admirável mundo novo prometido pela relação colonial-capitalista não aconteceu; pelo contrário, inúmeros são os desafios que se colocam para transformar e ultrapassar as situações de opressão e exploração que continuam. Muito do conhecimento que circula no Norte Global sobre África (e que geralmente se refere à África Subsaariana e tendem a ignorar o Norte da África) está moldado por uma estrutura alegórica maniqueísta, onde África é frequentemente vista como exemplo de tudo o que é incompleto, inacabado, caracterizado por extremos pobreza, corrupção, má administração, guerra, etc. (MBEMBE, 2001). Em suma, como vários autores têm vindo a apontar, a produção de conhecimento África, a partir de uma perspetiva eurocêntrica, acompanhou e possibilitou a realização da colonização. Neste sentido, a emancipação política é, também, um exercício de produção de conhecimento, um acto de libertação, um desafio constante à narrativa presente em qualquer biblioteca colonial (MUDIMBE, 1988).

Como sublinhou Amílcar Cabral (2016), importa refletir académica e politicamente, a partir de uma perspetiva critica, sobre os instrumentos analíticos de que dispomos para 
analisar o espaço colonial e para interpelar o colonizador metropolitano. Ampliando este desafio, Boaventura de Sousa Santos (2014) alerta para o facto de muitos dos conceitos, teorias e análises de que dispomos hoje, porque produzidos a partir de contextos eurocêntricos, são insuficientes para caracterizar o nosso tempo e sugerir soluções para uma transformação radical da nossa realidade.

Uma das razões para o fosso existente entre as fortes perguntas que as realidades politicas colocam e a fracas respostas que as teorias politicas contemporâneas oferecem decorre do fato de que grande parte da tradição intelectual que estrutura o pensamento político dominante foi construído ao lado de trajetórias políticas e históricas imperiais e/ou liberais (AMIN, 1974; DUSSEL, 1993). Em paralelo, muitas interpretações do mundo e explicações de lutas foram eclipsadas do mapa epistemológico porque não se coadunavam com as propostas e possibilidades teóricas avançadas pelos modernos teóricos eurocêntricos.

A leitura dos desafios contidos em vários dos textos que integram este volume sugere que os tempos atuais exigem uma renovada militância do propósito das lutas, das resistências, uma disposição para assumir riscos para a justiça e a necessidade urgente de redes ainda mais amplas e repletas de solidariedade humana. Audre Lorde sublinhava, há alguns anos, que não se poderia nunca considerar livre "enquanto houver uma mulher não-livre, mesmo que as suas grilhetas sejam diferentes das minhas" (2007: 132), antecipando a necessidade de uma tradução intercultural potenciando os saberes produzidos nessas lutas politicas e sociais, saberes que são contextuais (SANTOS E CRUZ E SILVA, 2004).

No caso específico de Moçambique, que ocupa o lugar central neste dossier, um dos temas dominantes está centrado na crise financeira e económicas no país, uma realidade que é partilhada com várias regiões do globo. Na origem destas crises estão vários fatores, de ordem económica e política. Porém, a centralidade das interpretações herdadas das bibliotecas coloniais leva a que a experiência da crise em Moçambique seja menorizada e menos conhecida.

Nos dias que correm, após o deslumbramento do boom dos recursos naturais que marcou o país durante a primeira década do século XX, Moçambique experimenta um contexto de crise, caracterizado por um aumento dos índices da pobreza, por uma importante dívida pública, cujo impacto se faz sentir na redução do Orçamento do Estado em várias áreas 
centrais, como a saúde e a educação (CASTEL-BRANCO, 2015). Com uma população maioritariamente jovem (cerca de $33 \%$ da população), a crise afeta, sobretudo, esta faixa etária, comprometendo o seu presente e as perspetivas de um 'futuro melhor' (PLATAFORMA DE JOVENS LÍDERES, 2017). Outra força importante são as mulheres, que se ressentem mais ainda deste contexto de crise, ao qual se acrescentam os condicionalismos socioculturais que ainda limitam o seu acesso à educação, por exemplo, afetando o seu presente e futuro. As mulheres e os jovens, pelo peso que representam, são o garante da edificação da nação moçambicana e força motriz na promoção do seu desenvolvimento. As suas lutas pelo acesso à saúde, habitação, educação, à terra (num contexto onde a maioria da população é ainda rural), desafiando os megaprojetos, são elementos que marcam o espaço politico moçambicano, do que nos dão conta vários dos artigos que integram este dossier, espelho da complexidade da sociedade moçambicana contemporânea.

No seu conjunto, estes artigos convocam um saber que exige novas relações ética, e que é performativo, curativo, transformador e participativo, um saber que procura atender às necessidades individuais e coletivas das pessoas e comunidades comuns. É um saber que está comprometido com o diálogo, com a aprendizagem mútua e diálogo. Trata-se de uma forma de produção de conhecimento responsabilizada não apenas em prol da pesquisa, mas a pesquisa que prevalece nos conhecimentos, vozes e experiências autóctones. E por isso o nosso convite, com este dossiê que se estende com a Seção Pautas Insubmissas que também trata de Moçambique, a ampliar os diálogos insubmissos a Sul.

\section{REFERÊNCIAS}

AMIN, Samir. Accumulation on a World Scale: a critique of a theory of underdevelopment. New York: Monthly Review Press, 2 vol, 1974

CABRAL, Amílcar. "Libertação Nacional e Cultura”, em MONDAINI, M. (ed.), Cultura em Tempos de Libertação Nacional e Revolução Social: Amílcar Cabral, Samora

Machel e Mário de Andrade. Recife: UFPE, p. 31-58, 2016 [1970] 
CASTEL-BRANCO, Carlos Nuno. "Desafios da Sustentabilidade do Crescimento Económico: uma ‘Bolha Económica' em Moçambique?” em BRITO, L. et al. (orgs.), Desafios para Moçambique. Maputo: IESE, p. 157-200, 2015.

DUSSEL, Enrique. “Europa, Modernidad y Eurocentrismo”, Revista de Cultura Teológica, 4: 69-81, 1993.

LORDE, Audre. Sister Outsider: Essays and speeches by Audre Lorde. Berkeley: Crossing Press, 2007.

MBEMBE, Achille. On the Postcolony. Berkeley: University of California Press, 2001.

MENESES, Maria Paula. “A questão negra entre continentes: possibilidades de tradução intercultural a partir das práticas de luta”, Sociologias, 18 (43): 176-206, 2016.

MUDIMBE, Valentin Y. The Invention of Africa. Gnosis, philosophy, and the order of knowledge. Bloomington, IN: University of Indiana Press, 1988.

PLATAFORMA DE JOVENS LÍDERES. A Juventude Moçambicana e Crise Económica alternativas criativas. Relatório do Workshop realizado em Maputo, com apoio da Fundação Friedrich Ebert, 2017.

SANTOS, Boaventura de Sousa. Epistemologies of the South. Justice against Epistemicide. New York: Routledge, 2014.

SANTOS, Boaventura de Sousa; CRUZ E SILVA, Teresa. Moçambique e a reinvenção da emancipação social. Maputo: Centro de Formação Jurídica e Judiciária, 2004.

THIONG'O, Ngugi wa. Decolonizing the Mind. The struggle for cultural freedoms. London: James Currey, 1993. 